\title{
Use of a Palm Oil-Based Imidazoline as Corrsion Inhibitor for Copper in 3.5\% NaCl Solution
}

\author{
J.G. Gonzalez-Rodriguez, ${ }^{1, *}$ J. Porcayo-Calderon ${ }^{1}$, E. Vazquez-Velez ${ }^{2}$, L.M. Martinez de la Escalera ${ }^{3}$, \\ J. Canto ${ }^{3}$, L. Martinez $z^{2,3}$ \\ ${ }^{1}$ CIICAp, Universidad Autonoma del Estado de Morelos, Avenida Universidad 1001, 62209 \\ Cuernavaca, Mor., Mexico \\ ${ }^{2}$ Instituto de Ciencias Fisicas, Universidad Nacional Autonoma de Mexico, Avenida Universidad s/n, \\ 62210 Cuernavaca, MOR, Mexico \\ ${ }^{3}$ Corrosion y Proteccion (CyP), Buffon 46, 11590 Mexico City, DF, Mexico \\ *E-mail: ggonzalez@uaem.mx
}

doi: $10.20964 / 2016.10 .46$

Received: 3 March 2016 / Accepted: 6 April 2016 / Published: 6 September 2016

A palm-oil modified hydroxyethyl imidazoline has been used as corrosion inhibitor for $\mathrm{Cu}$ in $3.5 \%$ $\mathrm{NaCl}$ solution by using potectiodynamic polarization curves, linear polarization resistance (LPR) and electrochemical impedance spectroscopy (EIS) measurements. Results showed that modified imidazoline acts as good inhibitor for $\mathrm{Cu}$ and its efficiency increases with increasing its concentration and exposure time. It was found that modified imidazoline contains compounds with heteroatoms within their molecular structure which act as sites to be chemically adsorbed on to the $\mathrm{Cu}$ surface, by following a Langmuir type of isotherm, to form protective corrosion products.

Keywords: copper, corrosion, imidazoline.

\section{$\underline{\text { FULL TEXT }}$}

(C) 2016 The Authors. Published by ESG (www.electrochemsci.org). This article is an open access article distributed under the terms and conditions of the Creative Commons Attribution license (http://creativecommons.org/licenses/by/4.0/). 